\title{
Efficacy of Vertebral Augmentation for Vertebral Compression Fractures: A Review of Meta-Analyses
}

\author{
William Luo ${ }^{1)}$, Christina Cui ${ }^{1)}$, Sina Pourtaheri' ${ }^{2)}$ and Steven Garfin ${ }^{2)}$ \\ 1) School of Medicine, University of California San Diego, La Jolla, CA, USA \\ 2) Department of Orthopaedic Surgery, University of California San Diego, San Diego, CA, USA
}

\begin{abstract}
:
Introduction: Vertebral compression fracture incidence is rising with the growth of the geriatric population and is one of the leading disabilities in healthcare. However, the literature is conflicted on the benefits of vertebral augmentation versus nonoperative care for these fractures. The purpose of the current study was to perform a review of all meta-analyses in the literature comparing vertebral augmentation to nonoperative care and descriptively report the results.
\end{abstract}

Methods: A review of all meta-analyses evaluating trials of vertebral augmentation compared with nonoperative care was performed. The primary outcome studied was pain. Secondary outcomes were quality of life (QoL) metrics and functional outcomes.

Results: Ten studies met the inclusion criteria. Besides two sham procedure studies, the remaining literature concluded that vertebral augmentation was superior to nonoperative care for reducing back pain. The reporting of secondary outcomes, such as QoL metrics and functional outcomes, was heterogeneous among the studies. Studies that reported these secondary outcomes, however, did identify some early benefit in vertebral augmentation.

Conclusions: The current literature suggests vertebral augmentation is more effective in improving pain outcomes compared with nonoperative management. While more studies are needed to conclusively assess vertebral augmentation's efficacy in improving functional outcome and QoL, the meta-analyses surveyed here suggest that at least some benefit exists when assessing these two outcomes.

Keywords:

compression fracture, vertebral compression fracture, osteoporosis, kyphoplasty, vertebroplasty, cement augmentation

Spine Surg Relat Res 2018; 2(3): 163-168

dx.doi.org/10.22603/ssrr.2017-0089

\section{Introduction}

Vertebral compression fractures (VCFs) are the most common type of fractures seen with osteoporosis. While only $30 \%-40 \%$ of VCFs are symptomatic, the resulting back pain can severely limit a patient's ability to perform activities of daily living ${ }^{1)}$.

Percutaneous vertebral augmentation (PVA) is an intervention used to treat osteoporotic or pathologic VCFs. Two types of PVA are used: vertebroplasty (VP) and kyphoplasty (KP). VP involves the injection of cement into the affected vertebral body, while KP involves the inflation of a surgical balloon to create a cavity and, in some cases, correct the deformity prior to cement injection. Risks of PVA include direct nerve injury, cement extravasation, bleeding, and em- bolic events ${ }^{2)}$.

The goal of PVA is to stabilize the fracture to manage the debilitating symptoms associated with VCFs, and, with KP, improve the deformity, if possible. Retrospective studies have shown that both KP and VP provide effective pain reduction in patients suffering from $\mathrm{VCFs}^{3,4)}$.

In 2009, two randomized controlled trials (RCTs) published by Buchbinder et al. and Kallmes et al. in the New England Journal of Medicine reportedly showed that VP had no benefit over a sham procedure in patients suffering from back pain, presumably due to $\mathrm{VCFs}^{5,6}$. Since then, the role of VP and PVA in treating osteoporotic VCFs has been controversial. A systematic review published in 2012 by Maturitas studying RCTs concluded that PVA provided significant pain relief compared with placebo or nonsurgical manage-

Corresponding author: Steven Garfin, sgarfin@ucsd.edu

Received: November 28, 2017, Accepted: January 11, 2018, Advance Publication: April 7, 2018

Copyright (C) 2018 The Japanese Society for Spine Surgery and Related Research 


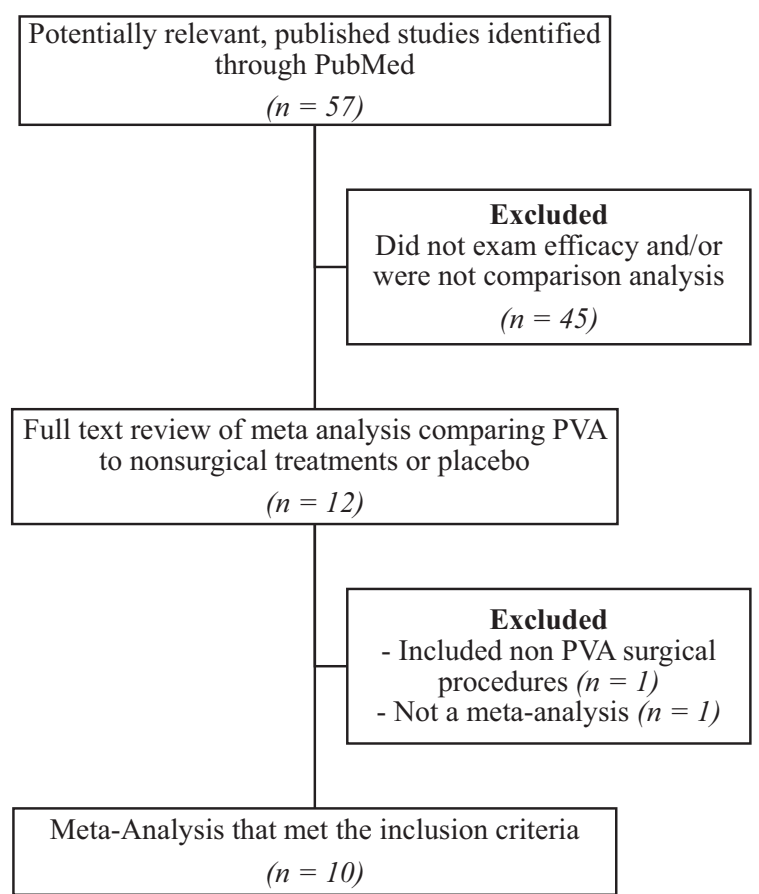

Figure 1. This figure displays the methodology used in the literature search conducted for this review.

ment ${ }^{7}$. However, it should be noted that the trials that reported benefit in PVA did not use sham controls, while Buchbinder and Kallmes ${ }^{5,6}$ did use sham controls. As of August 2017, in the past 2 years no trials that assess PVA outcomes were reported. The objective of this review is to present and discuss the findings of meta-analyses that have examined the question of PVA efficacy in treating of VCFs, due to the lack of consensus on its efficacy.

\section{Materials and Methods}

Meta-analyses available in English full text on PubMed that examined human trials comparing the efficacy of PVA (VP, KP, or both) with placebos or nonsurgical management were included for review. The primary outcome examined was pain scores. Secondary outcomes included quality of life $(\mathrm{QoL})$ and functional scores.

The following search terms were used in PubMed to obtain our studies:

("vertebral augmentation" [All Fields] OR ("vertebroplasty"[MeSH Terms] OR "vertebroplasty" [All Fields])) OR ("kyphoplasty" [MeSH Terms] OR "kyphoplasty" [All Fields]) AND (Meta-Analysis [ptyp] AND "loattrfull text" [sb] AND "humans" [MeSH Terms] AND English[lang])

\section{Results}

\section{Description of studies}

The search yielded 57 studies that reviewers checked for inclusion by reading through the studies' abstracts. 45 were excluded because they either did not compare PVA to non- surgical treatments or placebo or because they did not examine efficacy. The remaining 12 studies underwent full text review. One study was excluded for including non-PVA surgical procedures in its meta-analysis, while another was excluded because it was not a meta-analysis. The 10 remaining meta-analyses were reviewed and discussed. All 10 studies included were meta-analyses of prospective trials examining the efficacy of VP, KP, or both compared with control cohorts. A summary of the inclusion and exclusion process is shown in Fig. 1. Of the 10 meta-analyses, three compared both VP and KP against control cohort ${ }^{8.10}$ and seven compared VP to control cohorts ${ }^{11-17}$. Characteristics and findings of the 10 studies are summarized in Table 1. When combined, the 10 meta-analyses examined a total of 22 trials. The distribution of these trials among the 10 meta-analyses is shown in Table 2.

Of the 22 trials, three used sham surgical procedures as their control groups. These studies are marked in Table 2. The remaining 18 studies used nonsurgical management as their control groups.

\section{Pain outcomes}

All three meta-analyses that compared PVA with control concluded that PVA provided a statistically significant improvement in pain outcomes compared with controls. Of the seven meta-analyses that compared only VP with control, two concluded that no statistical difference in pain outcomes could be seen between VP and control group ${ }^{12,17}$. The remaining five all concluded that VP reduced pain significantly more than in control groups ${ }^{11,13-16)}$.

\section{Functional outcomes}

Of the three PVA meta-analyses, one examined functional outcomes and concluded that PVA afforded significant improvement in functional outcomes compared with controls ${ }^{8)}$. The two VP meta-analyses that reported on functional outcomes both concluded that no difference in functional outcomes existed between VP and control groups ${ }^{12,17)}$.

\section{QoL outcomes}

QoL measurements include pain-related disabilities, European Quality of Life-5 Dimensions, Quality of life Questionnaire of the European Foundation for Osteoporosis, and Roland-Morris Disability Questionnaire ${ }^{8,915)}$. Only two out of the three PVA meta-analyses studied QoL; both found that PVA provided statistically significant better outcomes. There were three VP meta-analyses that studied QoL, two concluded PVA led to significantly better QoL, while one found no statistically significant difference in QoL outcomes.

\section{Discussion}

PVA, including both KP and VP, is frequently used to treat acute VCFs; however, there has been recent controversy over its efficacy. In 2009, two RCTs published by Buchbinder et al. and Kallmes et al. concluded that VP 
Table 1. The Key Findings in the Meta-analyses Examined in This Review.

\begin{tabular}{|c|c|c|c|c|c|c|c|c|}
\hline Authors & $\begin{array}{c}\text { Year } \\
\text { published }\end{array}$ & $\begin{array}{l}\text { Studies } \\
\quad(n)\end{array}$ & $\begin{array}{l}\text { Treatment } \\
\text { compared }\end{array}$ & $\begin{array}{l}\text { Total } \\
\text { cases } \\
(n)\end{array}$ & $\begin{array}{l}\text { Pain } \\
\text { outcomes }\end{array}$ & $\begin{array}{l}\text { Functional } \\
\text { outcomes }\end{array}$ & $\begin{array}{c}\text { QoL } \\
\text { outcomes }\end{array}$ & Conclusion \\
\hline Yuan et al. ${ }^{8)}$ & 2016 & 10 & PVA & 1254 & $\begin{array}{c}\text { Favors } \\
\text { PVA } * * *^{*}\end{array}$ & $\begin{array}{l}\text { Favors } \\
\text { PVA }^{* * *}\end{array}$ & $\begin{array}{c}\text { Favors } \\
\text { PVA } * * *^{*}\end{array}$ & $\begin{array}{l}\text { PVA improves pain and func- } \\
\text { tional outcomes compared with } \\
\text { controls }\end{array}$ \\
\hline Mattie et al. ${ }^{11)}$ & 2016 & 11 & PVP & 1048 & $\begin{array}{l}\text { Favors } \\
\text { PVP } \dagger\end{array}$ & NR & NR & $\begin{array}{l}\text { PVP exceeds controls in pain } \\
\text { outcomes at } 1 \text { year }\end{array}$ \\
\hline Li et al. ${ }^{9)}$ & 2015 & 8 & PVA & 987 & $\begin{array}{l}\text { Favors } \\
\text { PVA }^{*} * *\end{array}$ & $\begin{array}{l}\text { Favors } \\
\text { PVA* }\end{array}$ & $\begin{array}{l}\text { Favors } \\
\text { PVA* }\end{array}$ & $\begin{array}{l}\text { PVA improves pain and QoL } \\
\text { significantly more than do } \\
\text { controls }\end{array}$ \\
\hline Buchbinder et al. ${ }^{12)}$ & 2015 & 12 & PVP & 1458 & $\begin{array}{c}\text { Not } \\
\text { significant }\end{array}$ & $\begin{array}{l}\text { Not } \\
\text { significant }\end{array}$ & $\begin{array}{l}\text { Not } \\
\text { significant }\end{array}$ & $\begin{array}{l}\text { No improvement in clinical } \\
\text { outcomes with vertebroplasty } \\
\text { over sham procedure }\end{array}$ \\
\hline Chen et al. ${ }^{18)}$ & 2015 & 5 & PVA & 777 & $\begin{array}{l}\text { Favors } \\
\text { PVA } \dagger\end{array}$ & NR & NR & $\begin{array}{l}\text { PVA significantly improves } \\
\text { pain outcomes compared with } \\
\text { nonsurgical management }\end{array}$ \\
\hline Tian et al. ${ }^{13)}$ & 2014 & 5 & PVP & 1057 & $\begin{array}{c}\text { Favors } \\
\text { PVA }^{* * * * * *}\end{array}$ & NR & NR & $\begin{array}{l}\text { Statistically significant im- } \\
\text { provement with PVP in pain } \\
\text { outcomes over conservative } \\
\text { treatment }\end{array}$ \\
\hline Liu et al. ${ }^{14)}$ & 2013 & 5 & PVP & 577 & $\begin{array}{l}\text { Favors } \\
\text { PVP**** }\end{array}$ & NR & NR & $\begin{array}{l}\text { PVP has moderate benefit over } \\
\text { controls for pain outcomes }\end{array}$ \\
\hline Anderson et al. ${ }^{15)}$ & 2013 & 6 & PVP & 612 & $\begin{array}{l}\text { Favors } \\
\text { PVP† }\end{array}$ & $\begin{array}{l}\text { Favors } \\
\text { PVP† }\end{array}$ & $\begin{array}{l}\text { Favors } \\
\text { PVP† }\end{array}$ & $\begin{array}{l}\text { Greater improvement in pain } \\
\text { outcomes, function, and QoL } \\
\text { seen in PVP compared with } \\
\text { nonsurgical treatment }\end{array}$ \\
\hline Shi et al. ${ }^{16)}$ & 2012 & 9 & PVP & 886 & $\begin{array}{l}\text { Favors } \\
\text { PVP**** }\end{array}$ & NR & $\begin{array}{l}\text { Favors } \\
\text { PVP* }\end{array}$ & $\begin{array}{l}\text { Greater improvement in pain } \\
\text { outcomes and QoL seen in } \\
\text { PVP vs. controls }\end{array}$ \\
\hline Staples et al. ${ }^{17)}$ & 2011 & 2 & PVP & 209 & $\begin{array}{c}\text { Not } \\
\text { significant }\end{array}$ & $\begin{array}{c}\text { Not } \\
\text { significant }\end{array}$ & NR & $\begin{array}{l}\text { Results fail to show that pa- } \\
\text { tients would benefit from PVP } \\
\text { compared with placebo }\end{array}$ \\
\hline
\end{tabular}

Abbreviations: $* p<0.05, * * p<0.01, * * * p<0.001, * * * * p<0.0001, * * * * * p<0.00001, \dagger$ Reported CI, NR=not reported

$\mathrm{PVA}=$ studies including both kyphoplasty and vertebroplasty versus nonoperative care; $\mathrm{PVP}=$ vertebroplasty-only studies versus nonoperative care.

showed no benefit to patients suffering from back pain compared with outcomes from a sham procedure control group $^{5,6)}$. These studies likely went on to influence practices, with the American Academy of Orthopaedic Surgeons noting that evidence supporting kyphoplasty in treating VCFs was limited but issued a strong recommendation against vertebroplasty $^{37)}$. The purpose of our study is to re-examine the conclusions set forth by Buchbinder and Kallmes in the context of other meta-analyses comparing PVA with nonoperative care. A total of 10 meta-analysis were examined, three comparing PVA with nonoperative care, seven comparing VP-only with nonoperative care. Of the 10 meta-analyses, 8 studies concluded that either PVA or VP conferred better pain outcomes than nonoperative care. Of the two that did not, one was Buchbinder et al.'s 2015 assessment that concluded that RCTs that did not use a sham procedure control were subject to bias. Therefore, less weight was placed on RCTs that did not use sham procedures. The other, by Staples et al., only included the two aforementioned studies by Buchbinder et al. and Kallmes et $\mathrm{al}^{17)}$. Both Buchbinder et al. and Kallmes et al.'s rationales were that a sham procedure was the only proper control for a RCT studying the efficacy of VP.
There are concerns with this approach. First, using only two studies greatly diminishes the power of Staples et al.'s meta-analysis. Second, a study published in 2015 by Guo et al. in the Public Library of Science noted that, while sham procedures such as the one documented by Buchbinder et al. ${ }^{5)}$ and Kallmes et al. ${ }^{6}$ are intended to be used as a control, they are still invasive procedures that can contribute a placebo effect in patients suffering from VCF-induced pain $^{38)}$. When vertebroplasty and sham procedure groups were considered together with other surgical procedures, pain outcomes were significantly better than those seen in nonsurgical management. Third, the inclusion criteria used by Buchbinder et al. and Kallmes et al. in their respective RCTs are concerning. Both studies included patients with back pain but failed to describe whether the back pain was confirmed to be caused by VCFs through clinical examination, the acuity of the fractures through history or advanced imaging (MRI and/or bone scan). Neither MRIs nor bone scans were performed at any time, either during preprocedure in assignment or postprocedure, to determine whether the polymethylmethacrylate had extravasated or new fractures had developed. The entry criteria were back pain and plain radiographs demonstrating a VCF. However, the latter 


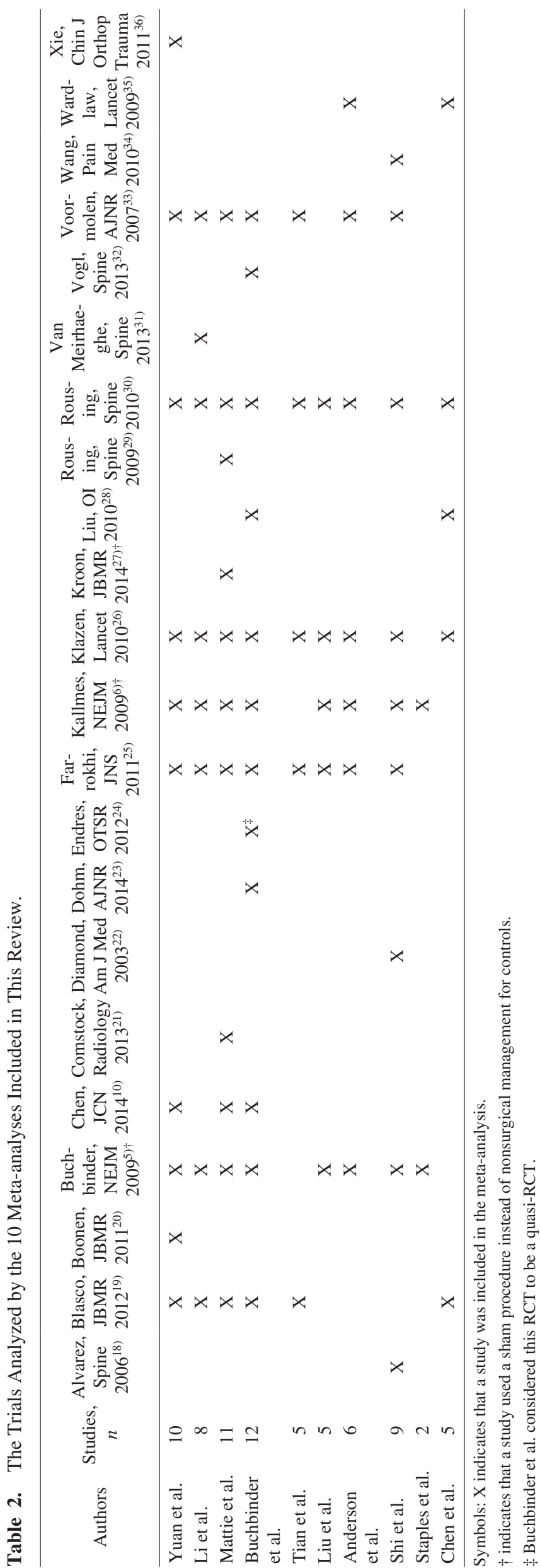

could have occurred at any time and/or completely healed and just incidental. The back pain could have been from many other causes. Also, without examining the patient they would not know if the pain was even at that location. Thus, there is a risk that patients who did not suffer from pain due to VCFs or patients with chronic/healed fractures were included, thus confounding pain outcomes. Moreover, the studies exhibited crossover rates toward VP as high as $47 \%$. Moreover, $40 \%-60 \%$ of patients who were truly eligible for these studies did not participate, thus bringing the generalizability of their findings into serious question. Flaws existed in their statistical analysis as well. Kallmes et al. changed their power analysis to compensate for low enrollment in the middle of their study. Similarly, Buchbinder et al. used a power analysis for multicenter studies, while roughly $70 \%$ of their patient sample came from a single center. Taken together, inadequate sampling, failure to perform physical exams and obtain proper imaging studies, and questionable statistical methods cast further doubt on the findings published by Buchbinder et al. and Kallmes et al. Furthermore, despite the findings published by Buchbinder et al. and Kallmes et al., Kallmes found that physicians, including him, have continued to offer patients with back pain secondary to VCFs PVA ${ }^{39}$.

While this review focused on meta-analyses of prospective studies on VA, retrospective studies supporting VA use exist as well. One such study examined patients diagnosed with osteoporotic VCFs between 1993 and 2006 and found that VA afforded a survival advantage over VCF patients treated with conservative management ${ }^{40)}$. Another singlecenter retrospective study examining healthcare costs found that while VA hospital stays cost more than medical management, VCF patients managed conservatively were subject to higher readmission rates than patients treated with $\mathrm{VA}^{41}$. These studies, while retrospective, further support VA as an efficacious and cost-effective means of treating VCFs.

\section{Limitations}

This review is limited by the weaknesses inherent in the included meta-analyses. Most of the meta-analyses studies noted significant heterogeneity among the controlled trials that they examined. Moreover, while all meta-analyses examined pain, functional outcomes and QoL scores were not uniformly assessed in all studies. QoL, specifically, is a useful tool to assess how patients themselves perceive their level of functionality and it is important to begin to uniformly assess this. QoL assessment tools, such as the Assessment of Quality of Life scales may offer additional insight into patients' daily lives and provide a patient-centered measure of VA's efficacy when employed in future trials ${ }^{42}$. Different time point studies (length of follow-up) by each meta-analysis and the bias inherent in choosing which trials to include or exclude also contributes to this heterogeneity. In any case, more controlled trials are needed to conclude whether PVA can improve pain, function and QoL in pa- 
tients suffering from VCFs.

\section{Conclusion}

Despite limitations, the current literature suggests vertebral augmentation is more effective at reducing pain compared with nonoperative care. Both prospective and retrospective studies support the use of PVA over nonsurgical management. Moreover, by failing to discern the source of their subjects' back pain and inconsistent sampling and statistical analysis, Buchbinder et al. and Kallmes et al. cannot objectively conclude that VP offers no advantage over a sham procedure. Furthermore, their failure to provide adequate preoperative and postoperative monitoring for their patients does not meet standards of evidence-based medicine. While more studies are needed to conclusively assess vertebral augmentation's efficacy in improving functional outcome and QoL metrics, the meta-analyses surveyed here suggest that at least some benefit in these two outcomes. The papers surveyed in this study represent the current best evidence that should be used to provide individual care patients suffering from VCFs. Thus, our review demonstrates that VP and KP are procedures with proven efficacy in affecting clinically relevant patient outcomes and are therefore not only acceptable but effective strategies in managing acute VCFs.

Conflicts of Interest: The authors declare no conflicts of interest, except Steven Garfin, MD: AO North America: Research support; Benvenue Medical: Paid consultant; DePuy, A Johnson \& Johnson Company: IP royalties; Paid consultant; Research support; EBI: Paid consultant; Research support; Elsevier: Publishing royalties, financial or material support; Globus Medical: Paid consultant; Research support; Harcourt: Publishing royalties, financial or material support; International Society for the Advancement of Spine Surgeons: Board or committee member; Intrinsic Therapeutics: Paid consultant; Journal of Bone and Joint Surgery - American: Editorial or governing board; Lippincott: Publishing royalties, financial or material support; Magnifi Group: Paid consultant; Medtronic: Research support; Mosby: Publishing royalties, financial or material support; Nuvasive: Paid consultant; Research support; SI Bone: Paid consultant; Stock or stock options; SLACK Incorporated: Editorial or governing board; Spinal Kinetics: Paid consultant; Spine: Editorial or governing board; Synthes: Research support; Thieme Publishers: Publishing royalties, financial or material support; Vertiflex: Paid consultant; Wolters Kluwer Health Lippincott Williams \& Wilkins: Editorial or governing board; Publishing royalties, financial or material support

Author Contributions: WL and CC wrote and prepared the manuscript, and all other participated in the study design. All authors have read, reviewed, and approved the article.

\section{References}

1. Makris UE, Reid MC. Back Pain and Spinal Stenosis. In: Halter JB, Ouslander JG, Studenski S, et al., eds. Hazzard's Geriatric Medicine and Gerontology, 7e. New York, NY: McGraw-Hill Education; 2017.

2. Rosenquist RW, Vrooman BM. Chapter 47. Chronic Pain Management. In: Butterworth JF, Mackey DC, Wasnick JD, eds. Morgan \& Mikhail's Clinical Anesthesiology, 5e. New York, NY: The McGraw-Hill Companies; 2013.

3. Kaufmann TJ, Jensen ME, Schweickert PA, et al. Age of fracture and clinical outcomes of percutaneous vertebroplasty. AJNR Am J Neuroradiol. 2001;22(10):1860-3.

4. Ledlie JT, Renfro MB. Kyphoplasty treatment of vertebral fractures: 2-year outcomes show sustained benefits. Spine (Phila Pa 1976). 2006;31(1):57-64.

5. Buchbinder R, Osborne RH, Ebeling PR, et al. A Randomized Trial of Vertebroplasty for Painful Osteoporotic Vertebral Fractures. N Engl J Med. 2009;361(6):557-68.

6. Kallmes DF, Comstock BA, Heagerty PJ, et al. A randomized trial of vertebroplasty for osteoporotic spinal fractures. N Engl J Med. 2009;361(6):569-79.

7. Robinson Y, Olerud C. Vertebroplasty and kyphoplasty-A systematic review of cement augmentation techniques for osteoporotic vertebral compression fractures compared to standard medical therapy. Maturitas. 2012;72(1):42-9.

8. Yuan W-H, Hsu H-C, Lai K-L. Vertebroplasty and balloon kyphoplasty versus conservative treatment for osteoporotic vertebral compression fractures: A meta-analysis. Medicine. 2016;95 (31):e4491.

9. Li L, Ren J, Liu J, et al. Results of vertebral augmentation treatment for patients of painful osteoporotic vertebral compression fractures: A meta-analysis of eight randomized controlled trials. PLoS One. 2015;10(9):e0138126.

10. Chen D, An ZQ, Song S, et al. Percutaneous vertebroplasty compared with conservative treatment in patients with chronic painful osteoporotic spinal fractures. J Clin Neurosci. 2014;21(3):473-7.

11. Mattie R, Laimi K, Yu S, et al. Comparing percutaneous vertebroplasty and conservative therapy for treating osteoporotic compression fractures in the thoracic and lumbar spine: A systematic review and meta-analysis. JBJS. 2016;98(12):1041-51.

12. Buchbinder R, Golmohammadi K, Johnston RV, et al. Percutaneous vertebroplasty for osteoporotic vertebral compression fracture. Cochrane Database Syst Rev. 2015;(4):CD006349.

13. Tian J, Xiang L, Zhou D, et al. The clinical efficacy of vertebroplasty on osteoporotic vertebral compression fracture: A metaanalysis. Int J Surg. 2014;12(12):1249-53.

14. Liu J, Li X, Tang D, et al. Comparing pain reduction following vertebroplasty and conservative treatment for osteoporotic vertebral compression fractures: A meta-analysis of randomized controlled trials. Pain Physician. 2013;16(5):455-64.

15. Anderson PA, Froyshteter AB, Tontz WL. Meta-analysis of vertebral augmentation compared with conservative treatment for osteoporotic spinal fractures. J Bone Miner Res. 2013;28(2):372-82.

16. Shi M-M, Cai X-Z, Lin T, et al. Is there really no benefit of vertebroplasty for osteoporotic vertebral fractures? A meta-analysis. Clin Orthop Relat Res. 2012;470(10):2785-99.

17. Staples MP, Kallmes DF, Comstock BA, et al. Effectiveness of vertebroplasty using individual patient data from two randomised placebo controlled trials: meta-analysis. BMJ. 2011;343:d3952.

18. Alvarez L, Alcaraz M, Perez-Higueras A, et al. Percutaneous vertebroplasty: functional improvement in patients with osteoporotic compression fractures. Spine (Phila Pa 1976). 2006;31(10):1113-8. 
19. Blasco J, Martinez-Ferrer A, Macho J, et al. Effect of vertebroplasty on pain relief, quality of life, and the incidence of new vertebral fractures: A 12-month randomized follow-up, controlled trial. J Bone Miner Res. 2012;27(5):1159-66.

20. Boonen S, Van Meirhaeghe J, Bastian L, et al. Balloon kyphoplasty for the treatment of acute vertebral compression fractures: 2-year results from a randomized trial. J Bone Miner Res. 2011;26(7):1627-37.

21. Comstock BA, Sitlani CM, Jarvik JG, et al. Investigational vertebroplasty safety and efficacy trial (INVEST): patient-reported outcomes through 1 year. Radiology. 2013;269(1):224-31.

22. Diamond TH, Champion B, Clark WA. Management of acute osteoporotic vertebral fractures: a nonrandomized trial comparing percutaneous vertebroplasty with conservative therapy. Am J Med. 2003;114(4):257-65.

23. Dohm M, Black CM, Dacre A, et al. A randomized trial comparing balloon kyphoplasty and vertebroplasty for vertebral compression fractures due to osteoporosis. AJNR Am J Neuroradiol. 2014; 35(12):2227-36.

24. Endres S, Badura A. Shield kyphoplasty through a unipedicular approach compared to vertebroplasty and balloon kyphoplasty in osteoporotic thoracolumbar fracture: A prospective randomized study. Orthop Traumatol Surg Res. 2012;98(3):334-40.

25. Farrokhi MR, Alibai E, Maghami Z. Randomized controlled trial of percutaneous vertebroplasty versus optimal medical management for the relief of pain and disability in acute osteoporotic vertebral compression fractures. J Neurosurg Spine. 2011;14(5):561-9.

26. Klazen CA, Lohle PN, de Vries J, et al. Vertebroplasty versus conservative treatment in acute osteoporotic vertebral compression fractures (Vertos II): An open-label randomised trial. Lancet. 2010; 376(9746):1085-92.

27. Kroon F, Staples M, Ebeling PR, et al. Two-year results of a randomized placebo-controlled trial of vertebroplasty for acute osteoporotic vertebral fractures. J Bone Miner Res. 2014;29(6):1346-55.

28. Liu JT, Liao WJ, Tan WC, et al. Balloon kyphoplasty versus vertebroplasty for treatment of osteoporotic vertebral compression fracture: A prospective, comparative, and randomized clinical study. Osteoporos Int. 2010;21(2):359-64.

29. Rousing R, Andersen MO, Jespersen SM, et al. Percutaneous vertebroplasty compared to conservative treatment in patients with painful acute or subacute osteoporotic vertebral fractures: threemonths follow-up in a clinical randomized study. Spine (Phila Pa 1976). 2009;34(13):1349-54.

30. Rousing R, Hansen KL, Andersen MO, et al. Twelve-months follow-up in forty-nine patients with acute/semiacute osteoporotic vertebral fractures treated conservatively or with percutaneous vertebroplasty: a clinical randomized study. Spine (Phila Pa 1976). 2010;35(5):478-82.

31. Van Meirhaeghe $\mathrm{J}$, Bastian L, Boonen $\mathrm{S}$, et al. A randomized trial of balloon kyphoplasty and nonsurgical management for treating acute vertebral compression fractures: vertebral body kyphosis correction and surgical parameters. Spine (Phila Pa 1976). 2013;38 (12):971-83.

32. Vogl TJ, Pflugmacher R, Hierholzer J, et al. Cement directed kyphoplasty reduces cement leakage as compared with vertebroplasty: results of a controlled, randomized trial. Spine (Phila Pa 1976). 2013;38(20):1730-6.

33. Voormolen MH, Mali WP, Lohle PN, et al. Percutaneous vertebroplasty compared with optimal pain medication treatment: shortterm clinical outcome of patients with subacute or chronic painful osteoporotic vertebral compression fractures. The VERTOS study. AJNR Am J Neuroradiol. 2007;28(3):555-60.

34. Wang HK, Lu K, Liang CL, et al. Comparing clinical outcomes following percutaneous vertebroplasty with conservative therapy for acute osteoporotic vertebral compression fractures. Pain Med. 2010;11(11):1659-65.

35. Wardlaw D, Cummings SR, Van Meirhaeghe J, et al. Efficacy and safety of balloon kyphoplasty compared with non-surgical care for vertebral compression fracture (FREE): A randomised controlled trial. Lancet. 2009;373(9668):1016-24.

36. En X, Hao DJ. Percutaneous kyphoplasty versus conservative treatment of acute and subacute osteoporotici vertebral compression fractures: A randomized controlled study. Chin J Orthop Trauma. 2011.

37. AAOS Guideline on The Treatment of Osteoporotic Spinal Compression Fractures: Summary of Recommendations: American Academy of Orthopedic Surgeons; 2010.

38. Guo J-B, Zhu Y, Chen B-L, et al. Surgical versus non-surgical treatment for vertebral compression fracture with osteopenia: A systematic review and meta-analysis. PLoS ONE. 2015;10(5):e 0127145 .

39. Luetmer MT, Kallmes DF. Have referral patterns for vertebroplasty changed since publication of the placebo-controlled trials? AJNR Am J Neuroradiol. 2011;32(4):647-8.

40. Gerling MC, Eubanks JD, Patel R, et al. Cement Augmentation of Refractory Osteoporotic Vertebral Compression Fractures: Survivorship Analysis. Spine. 2011;36(19):E1266-E9.

41. Flug J, Hanford A, Ortiz O. Vertebral augmentation versus conservative therapy for emergently admitted vertebral compression deformities: An economic analysis. Pain Physician. 2013;16(5):4415 .

42. Maxwell A, Ozmen M, Iezzi A, et al. Deriving population norms for the AQoL-6D and AQoL-8D multi-attribute utility instruments from web-based data. Qual Life Res. 2016;25(12):3209-19.

Spine Surgery and Related Research is an Open Access article distributed under the Creative Commons Attribution-NonCommercial-NoDerivatives 4.0 International License. To view the details of this license, please visit (https://creativeco mmons.org/licenses/by-nc-nd/4.0/). 